\title{
Impactos do jornalismo digital horizontal na técnica de agendamento e na construção de espaços de poder
}

\author{
Janaina Goulart \\ Universidade Católica de Brasília \\ janainagoulart@gmail.com \\ Alexandre Kieling \\ Universidade Católica de Brasília \\ askieling@gmail.com
}

\begin{abstract}
Resumo
O presente artigo se propõe a uma análise das reconfigurações dos processos jornalísticos a partir da horizontalização dos meios de comunicação nas dinâmicas de convergência entre a mídia de massa e as mídias sociais. Coloca-se a questão, desse ambiente semiótico-discursivo, a partir dos efeitos de sentido presentes na possível tentativa de agendamento por parte do jornal Folha de S. Paulo em relação à expectativa de crescimento do Produto Interno Bruto (PIB) do Brasil.
\end{abstract}

Palavras-chave: jornalismo, horizontalização, analógico, digital.

\begin{abstract}
This article proposes an analysis of the reconfigurations of journalistic processes from the flattening of the media in the convergence dynamics between the mass media and social media. It raises the question, in this semiotic-discursive environment, from the effects of meaning present in the possible attempt of scheduling by the Folha de S. Paulo newspaper in relation to the expected growth of Gross Domestic Product (GDP) of Brazil.
\end{abstract}

Keywords: journalism, flattening, analog, digital

\section{Introdução}

A perspectiva da centralidade dos meios de comunicação, objeto da teoria do meio, na sociedade contemporânea, objeto da teoria dos sistemas de função, é um conhecido debate do século XX que retoma sua força instigadora com a emergência dos meios digitais. Luhmann (2005) aponta que o que sabemos sobre o mundo no qual vivemos, sabemos pelos meios de comunicação; e que pelo fato de este sistema comunicar algo distinto de si mesmo, sua atuação é percebida como uma sequência de operações observadoras. O elevado nível de mediação incrementado pela horizontalização dos processos de comunicação midiática, que faz parte de nossa existência hoje, é promovido, sobretudo, pelo campo do jornalismo. 
Em tese, o ambiente de convergência entre os meios de comunicação analógicos e digitais tenderia a neutralizar a força da centralidade e o poder de agendamento do sistema midiático. A liberdade de manifestação e publicações nas redes computacionais operaria um contra-discurso que ofereceria resistência e provocaria constrangimento ao desenfreado agendamento midiático.

O que se pretende nesta comunicação é averiguar os impactos dos processos de produção, circulação e reconhecimento nas práticas de agendamento e construção de espaço de poder a partir de um evento econômico e seu tratamento num dos principais jornais do país que trabalha com convergência de mídias. Almeja-se analisar a gênese de uma possível tentativa de agendamento por parte do jornal Folha de S. Paulo em relação à perspectiva de crescimento do Produto Interno Bruto (PIB) do Brasil no ano de 2012, sob três perspectivas: teoria dos sistemas, esfera pública e agendamento.

Espera-se explorar as nuances de uma relação tênue entre comunicação, mídia e poder no Brasil, e como estas se contrapõem e/ou influenciam o poder político tomando com referência a análise de uma matéria de capa e sua respectiva produção.

Diante da crise econômica internacional, que ainda recai sobre os países europeus, e que começa a dar sinais de alívio nos Estados Unidos, entre 2012 e 2013 o Brasil passou por período de estagnação da economia, com intervenções do Estado no setor produtivo e diminuição gradual da taxa básica de juros (Selic) à época, culminando naquele momento em protestos do setor bancário, um dos principais motores do mercado financeiro.

A mídia, sabidamente, acompanha cada desdobramento da tensão produzida pelos eventuais desgastes do campo econômico e sua relação com o campo político. Como também noticia a flutuabilidade do crédito de cada um desses sistemas junto à opinião pública. Ora veicula-se a mensagem de que o modelo capitalista entrou em colapso porque não se sustentava; ora o Estado surge como o elemento de equilíbrio para apoiar a recuperação econômica; ora o Estado intervém demais.

As nuances desta relação interdependente entre o campo econômico e o político são mediadas, tanto entre os campos; quanto entre os campos e a esfera pública ${ }^{15}$. É sobre o exercício desta mediação que se pretende explorar o papel da mídia nas relações de poder. Observa-se que o elevado nível de mediação que faz parte de nossa existência é promovido sobretudo pelo campo do jornalismo, que é pressionado pelo campo econômico (BOURDIEU, 1997) e que pelo fato de o campo do jornalismo ser sujeito às pressões comerciais, acaba ele próprio exercendo uma pressão sobre os demais campos e estruturas de poder.

15 Pensamos esfera pública a partir da ampliação do conceito proposta por Habermas. Nas suas retomadas do tema o autor vai alertar que os canais de comunicação promovem intersecções, vínculos entre o público e o privado animando redes de interação por meio das quais "estruturas espaciais de interação simples são ampliadas e abstraídas" (p.98). E quanto mais há um afastamento da presença física e a atuação em espaços virtuais mediados pela mídia observa-se uma generalização da esfera pública.(p.93) HABERMAS, Jürgen.. Direito e democracia: entre facticidade e validade. Vol II. $2^{a}$ ed. Rio de Janeiro: Tempo Brasileiro, 2003b. 
Sabe-se que um dos principais mecanismos dos meios de comunicação, nesse contexto, está baseado na sua capacidade de incluir ou excluir temas na esfera pública. E ao incluir um tema, na sua capacidade de destacar ou suprimir determinados elementos - o que pode modificar inclusive seu sentido. Este agendamento, ou agenda-setting da pauta costuma funcionar porque

as pessoas tem tendência para incluir ou excluir de seus próprios conhecimentos aquilo que os mass media incluem ou excluem do seu próprio conteúdo. Além disso, o público tende a atribuir àquilo que esse conteúdo inclui uma importância que reflete de perto a ênfase atribuída pelos mass media aos acontecimentos, aos problemas, às pessoas. (SHAW, 1979 in WOLF, 2009, p. 144).

Quando a imprensa é submetida ao campo econômico; desde o modelo de negócio em si como empresa de comunicação, que depende de anunciantes; até às pressões de entidades exteriores à administração do meio de comunicação, o seu produto, notícia, e o seu atributo, credibilidade, correm sérios riscos, assim como a sociedade. Soma-se a essa realidade a crescente complexificação dos processos comunicacionais, com o ainda recente fenômeno da midiatização da comunicação (SODRÉ, 2006) em nossa sociedade.

[...] uma ordem de mediações socialmente realizadas - um tipo particular de interação, portanto, a que poderíamos chamar de tecnomediações - caracterizadas por uma espécie de prótese tecnológica e mercadológica da realidade sensível, denominada médium. Trata-se de dispositivo cultural historicamente emergente no momento em que o processo da comunicação é técnica e mercadologicamente redefinido pela informação, isto é, por um produto a serviço da lei estrutural do valor, também conhecida como capital. (SODRÉ, 2006, p. 20)

Entende-se, assim, que todos os sistemas compartilham um ambiente midiatizado, cujos impactos dos processos de produção, circulação e reconhecimento nas práticas de agendamento e construção de espaço de poder seriam observáveis. Sobretudo, pensando à luz da semiose social, perspectiva indicada por Verón (1993) baseada na premissa de que não existe um sistema discursivo por si, e sim, o discurso em todos os sistemas, evidenciando assim que é impossível descrever o processo de produção do discurso sem considerar suas condições de produção.

O estudo diante da referida tentativa de agendamento leva em consideração o contexto em que o veículo construiu sua intencionalidade discursiva. Neste marco, Verón (1993) destaca a operação de três instâncias primárias: a instância e condições de produção, de circulação e de reconhecimento, ou recepção, sendo que:

O conceito de circulação designa precisamente o processo através do qual o sistema entre condições de produção e condições de percepção é, por sua vez, produzido socialmente. 'Circulação' é pois o nome do conjunto de mecanismos que formam parte do sistema produtivo, que definem as relações entre 'gramática' de produção e 'gramática' de reconhecimento, para um discurso ou um tipo de discurso dado. [...] A análise discursiva de um determinado conjunto de texto deveria permitir, por um lado, 
a descrição de um campo de efeitos de sentido, campo determinado pelas operações discursivas que operam no material textual (as que definem o processo de produção). (VERÓN, 1993, p. 20)

Diante desse ambiente semiótico-discursivo possibilitado pela midiatização vamos analisar os efeitos de sentido presentes na possível tentativa de agendamento por parte do jornal Folha de S. Paulo em relação à expectativa de crescimento do Produto Interno Bruto (PIB) do Brasil no ano de 2012.

\section{Observando o observar}

Luhmann (2005) alerta sobre a necessidade de se observar o trabalho da imprensa, que é, em sua essência, observar. Historicamente, de acordo com Habermas (2003a), a burguesia ocupou o espaço entre o poder público do estado e poder privado do mercado, passando a organizar-se na forma de sociedade civil e buscando participar ativamente de decisões políticas que interferissem de alguma maneira em seus respectivos sistemas de produção.

Este movimento traz consigo o surgimento de uma esfera social interessada no aspecto público e político do estado e da sociedade representada também por interesses diversos como artistas, acadêmicos, e religiosos, entre outros, porém, influenciada, e em grande medida, liderada pela burguesia, que estendia seus interesses aos demais segmentos da sociedade.

Neste contexto, a imprensa surge como um terceiro elemento, capaz de estabelecer uma interseção entre setor público e privado, institucionalizando teoricamente um canal permanente de debate. "A refuncionalização do princípio da esfera pública baseia-se numa reestruturação da esfera pública enquanto uma esfera que pode ser apreendida na evolução de sua instituição por excelência: a imprensa" (HABERMAS, 2003a, p. 212).

Entretanto, a própria gênese da imprensa estava direcionada a atender interesses comerciais, servindo como veículo de informações mercadológicas. Ainda que o jornalismo literário e de opinião tenham sido fortalecidos em seguida, prevaleceu o modelo mercadológico dos veículos de comunicação tal como se pode observar hoje.

O jornal Folha de S. Paulo faz parte deste contexto. Quando o veículo assumiu publicamente seu posicionamento mercadológico, como aponta Novelli (2001), este estava cercado de contradições. Naturalmente o jornalismo crítico, pluralista, apartidário e moderno junto à prática comercial e publicitária impossibilitaria oferecer ao leitor um conteúdo imparcial.

Trazendo para os dias atuais, aquela burguesia seria representada pelo setor produtivo privado, que domina quase a totalidade do sistema econômico, e do qual o próprio jornal Folha de S. Paulo faz parte, na condição de empresa de comunicação. Portanto, para atingir a esfera pública, estes sistemas se utilizam de suas características entre si, ora de uma maneira, ora de outra.

$\mathrm{Na}$ tentativa de ilustrar a correlação entre poder econômico, poder político e poder midiático, esta análise se debruça sobre dois exemplos que tratam o mesmo tema da editoria 
de Economia. O primeiro é da Folha de S. Paulo no qual se registra uma abordagem que demarca um posicionamento editorial que, como se sabe, balizou o tom das coberturas subsequentes nas ações do governo federal, especialmente do campo econômico. O segundo é do Estado de São Paulo que sempre se posicionou criticamente no tratamento das atividades do governo. Embora a amostra aqui proposta seja pontual e não se reúna um largo contingente de textos disponíveis, observe-se que o que nos ocupa é um exercício da proposta de articulação analítica entre teoria dos sistemas, esfera pública e agendamento, já referido.

Um dos exemplos é a matéria veiculada no jornal Folha de S. Paulo no dia 26 de dezembro de 2012, intitulada "Renda per capita do país cai com 'pibinho'". O PIB é a soma total da riqueza produzida no país. O PIB per capita representa a distribuição desta riqueza entre a população.

O material jornalístico discorre sobre as perspectivas do resultado do Produto Interno Bruto (PIB) do Brasil em 2012, apresentando um estudo encomendado pelo próprio veículo a uma consultoria de economia internacional para analisar o quanto o PIB per capita havia diminuído nos últimos anos, em dólares, a partir das prévias de resultado do PIB dos primeiros três trimestres do ano. Trechos da matéria demonstram alguns dos critérios do veículo ${ }^{16}$ :

A renda dos brasileiros medida em dólares deverá sofrer o maior recuo em uma década em 2012 provocada pela expansão fraca do PIB (Produto Interno Bruto) e pela desvalorização do real. [...]

Como essa expansão da economia teve ritmo próximo ao do crescimento da população, a renda per capita ficará estagnada em reais. Mas recuará em dólares, já que a moeda brasileira se desvalorizou nesse período.

Segundo cálculos feitos pela consultoria EIU (Economist Intelligence Unit) a pedido da Folha, o PIB per capita em dólares deverá sofrer uma contração de cerca de $9 \%$ este ano, para US\$11.670.

Será a queda mais forte desde 2002, quando houve recuo de 9,6\%. Em 2009, o PIB per capita em dólares também caiu $(2,9 \%)$ com uma recessão que, no entanto, foi parcialmente compensada por uma valorização do real. (FRAGA, 2012, p. 11)

A produção do referido conteúdo acontece em um ambiente midiatizado, do qual todos os sistemas envolvidos - político, econômico e midiático - comungam. Na versão digital da matéria se observa um número relativamente baixo de engajamento direto do público nas mídias sociais (ver Figura 1), com 1.300 recomendações pelo Facebook e 200 publicações na mídia Twitter. Também o número de comentários foi baixo para os padrões da Folha de $\mathrm{S}$. Paulo, com 268 registros.

16 Matéria completa disponível no ANEXO A. 


\title{
Renda per capita dos brasileiros cai com 'pibinho' de 2012
}

\author{
ÉRICA FRAGA \\ DE SÃO PAULO \\ $26 / 12 / 2012 \odot 04 h 30$

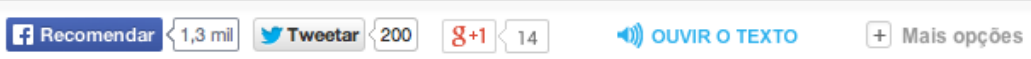 \\ coment $\square$ rios $\quad$ Ver todos os comentarios (268) \\ Comentar esta reportagem \\ Fonte: Folha de S. Paulo
}

Ainda que não estejamos avaliando a amplitude da repercussão no universo digital consequente deste engajamento direto, é possível evidenciar que estes números destoam da capacidade instalada que o veículo possui em seu total de seguidores, que hoje é de 1,16 milhão de seguidores no Twitter e mais de três milhões no Facebook.

Dado o número baixo de engajamento direto, por uma série de fatores, entre eles o tema em si, que de fato não se mostra como de grande interesse da sociedade em geral, e o período, que historicamente demonstra diminuição do ritmo de atividades das mídias sociais, o que se percebe é que houve interesse de outros veículos de comunicação que possuem estatura similar à da Folha de S. Paulo. O fato é que, aparentemente, o propósito discursivo do jornal não obteve o reconhecimento e a circulação desejada no ambiente das redes sociais. 0 agendamento só encontrou repercussão entre os meios de massa.

\section{Análise}

Para fundamentar e validar a pauta que desejava publicar, o veículo (FOLHA DE SÃO PAULO) recorreu a outro sistema, o econômico, por meio da consultoria econômica internacional. Neste sentido, é importante justamente analisar as escolhas, critérios e recortes para a produção desta notícia a fim de identificar se há de fato elementos que corroboram a preponderância do campo econômico sobre o campo jornalístico e seu respectivo efeito sobre os demais campos.

A começar pela escolha do tema para uma matéria de capa, por que o "PIB per capita"; em um segundo momento, o recorte de tempo, que polarizou dois governos de partidos distintos, desde 2002; um terceiro elemento, o critério do enquadramento e a ênfase da renda em dólares; e por último, a data de publicação da matéria em um período de baixa repercussão midiática de uma maneira geral.

A opção pelo PIB per capita, e não apenas PIB, faz com que o tema seja melhor entendido pela maior parte da população, visto que demonstrar o que isto significa individualmente pode ser mais efetivo. A escolha por uma consultoria internacional para 
analisar os números do Brasil parece justificar de alguma forma a escolha por demonstrar os valores da renda per capita em dólares.

No título da capa do jornal, Renda per capita do país tem queda após 'pibinho', isto não está claro, portanto a chamada principal não condiz com o conteúdo da matéria e há uma grande diferença entre as duas moedas, considerando que em 2012 houve valorização do dólar e desvalorização do Real. Isto significa que o "abismo" colocado na matéria é potencializado por usar uma cifra que não é a moeda local.

Figura 2 - Capa do jornal Folha de S. Paulo em 26 de dezembro de 2012

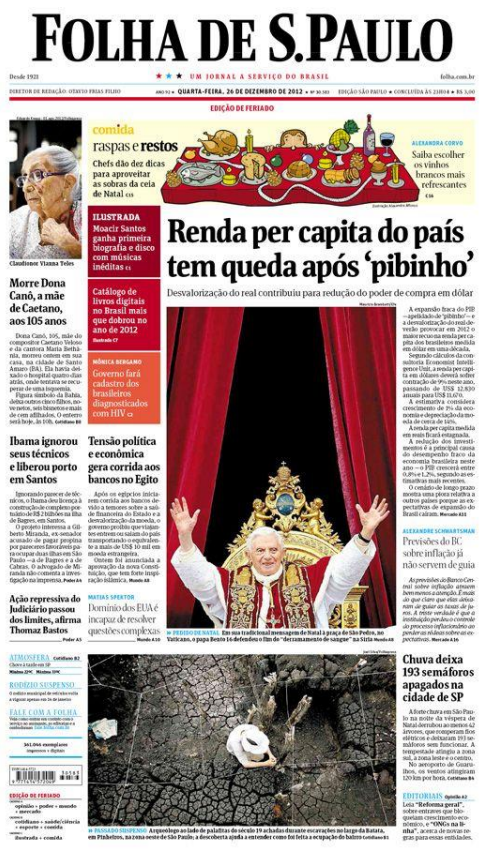

Fonte: Folha de S. Paulo

O Brasil adota há alguns anos o câmbio flutuante, de maneira que, qualquer recorte que se tente fazer sobre o país utilizando o dólar, pode ser totalmente desacreditado no dia seguinte a depender da taxa do dia - que é construída com base em uma série de fatores que oscilam. E a análise básica é: se o país cresce a uma taxa maior que $1 \%$ ao ano e o PIB do corrente ano é de $1 \%$, obviamente a renda per capita fica estagnada. Dessa forma o título e a chamada de capa - o que a maior parte das pessoas lê - só pode direcionar para uma única leitura.

Há uma aparente seleção de recortes para tornar a informação mais impactante do que realmente é, que poderia ser estendida à própria encomenda do estudo. Depois desta notícia, o veículo continuou extraindo manchetes menores a partir do mesmo estudo por três dias consecutivos.

No dia 26 de dezembro de 2012, quando a matéria foi publicada, e nos dias subsequentes, o acompanhamento sobre o tema não evidenciou alcance da matéria na esfera pública. McCombs (2004) empregou pela primeira vez o conceito de agendamento intermídia, 
em que as organizações noticiosas de maior status definem as agendas de outras organizações noticiosas. Não parece ter acontecido este movimento em relação à matéria analisada.

Dentre os conteúdos mais consistentes, destaca-se um comentário da jornalista e colunista Miriam Leitão, no jornal matinal da rádio $C B N$ e uma matéria publicada no dia seguinte no jornal O Estado de S. Paulo. O jornal O Globo não registrou menção ao tema, assim como o jornal Valor Econômico, que pertence ao grupo Folha.

$\mathrm{Na}$ televisão também não houve acompanhamento do tema, dentre os principais telejornais do horário nobre do país: Jornal Nacional, Jornal da Globo, Jornal da Record e Jornal da Band.

Recorrendo à Internet, as buscas pelo tema não demonstram aumento significativo. Os termos pesquisados foram "PIB per capita" e "Renda per capita", conforme gráficos a seguir:

\section{Figura 3 - Pesquisa pelo termo PIB per capita}

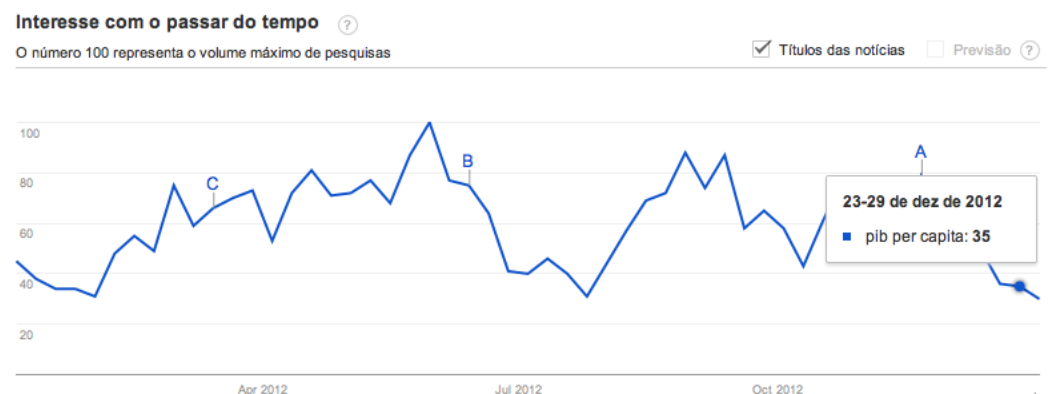

Fonte: Google Trends

\section{Figura 4 - Pesquisa pelo termo "Renda per capita"}

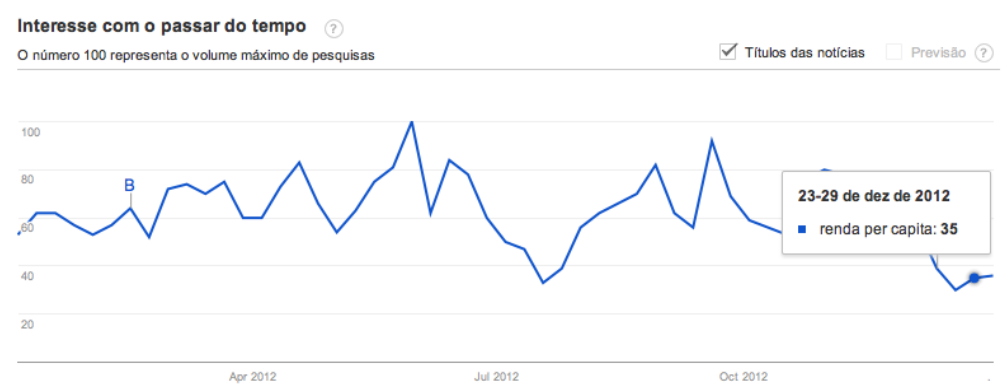

Fonte: Google Trends

O comentário da jornalista e colunista Miriam Leitão foi cético em relação às previsões de longo prazo, assim como detalhou as escolhas da pesquisa e consequentemente da notícia. Obviamente a colunista representa um veículo concorrente e esta informação é relevante.

O jornal O Estado de S. Paulo publicou uma matéria em seu portal digital sobre o tema, mas com enfoque contrário e fontes distintas da Folha de S. Paulo, o que não deixa de ser uma forma de agendamento também. A matéria, intitulada Estudo: PIB per capita cresce mais de 
50\% em 4 áreas, trouxe outro olhar para o mesmo tema econômico, usando de estratégias similares de produção jornalística' ${ }^{17}$ :

[...] Um dos pontos mais relevantes é o que comprova a descentralização da economia brasileira nos últimos anos. "O Produto Interno Bruto (PIB) per capita cresceu pelo menos 33\% em todas as 13 regiões metropolitanas, mas em quatro (Grande Vitória, Recife, Curitiba e Baixada Santista) a expansão superou os 50\%", afirmou o pesquisador sênior da Brookings, Jill Wilson, lembrando que os dados comparam a situação do Brasil em 1990 e 2012. $\square[\ldots]$

$\mathrm{Na}$ avaliação de Wilson, o Brasil já pode ser considerado uma potência econômica global. "Ao longo das últimas três décadas, uma série de líderes políticos adotou medidas para estabilizar o País e fundar as bases para uma economia nova e dinâmica." $\square \square$ Apesar da melhora, o pesquisador nota que o País precisa avançar mais, sobretudo em termos de PIB per capita. "A maioria das regiões metropolitanas brasileiras tem uma renda per capita inferior à das regiões metropolitanas de países desenvolvidos, com exceção de Brasília", disse. [...] (MODÉ, 2012)

Dados os interesses dos concorrentes e seus respectivos posicionamentos, parece haver ocorrido uma batalha discursiva, em que o sistema midiático, sob uma autorreferência, desencadeia irritações mútuas entre os dois principais jornais impressos do país, assim como a estação de rádio mais ouvida no país entre os formadores de opinião.

Aqui, o processo de reconhecimento e circulação demonstrado pelos veículos parece estar mais ligado à suas próprias capacidades de analisarem dados e darem sua leitura de mundo, do que necessariamente um serviço público. Continuam prevalecendo os interesses mercadológicos, seja por audiência, seja por posicionamento no ambiente midiático.

Percebemos a existência de um possível interagendamento ${ }^{18}$ entre veículos, porém não parece haver ocorrido agendamento do tema junto ao público, entendendo como a intencionalidade discursiva do jornal Folha de S. Paulo, ao encomendar um estudo para compor uma matéria de capa. O agendamento entre veículos parece estar mais ligado ao fato de que os concorrentes não poderiam deixar que a Folha de S. Paulo controlasse esta seara de discussão do que necessariamente um intuito informativo ou qualitativo.

\section{Conclusão}

Com base na notícia analisada, a relação que se pode observar entre os campos econômico, político e midiático, é que, em um primeiro momento, há uma atuação do campo da imprensa, utilizando-se do sistema econômico para atingir de alguma forma o sistema político. Porém, voltando à gênese da imprensa, a conclusão é de que o campo econômico usa do seu mecanismo imprensa para atingir o campo político, seja com a finalidade de lograr mais investimentos, ou qualquer outra.

17 Matéria completa disponível no ANEXO B.

18 Ocorre interagendamento quando determinado meio de comunicação é capaz de agendar um tema junto a outro meio de comunicação, influenciando os temas que o segundo incluirá em sua pauta. 
O sistema dos meios de comunicação não só está a serviço do sistema econômico, como faz parte do mesmo, de acordo com Luhmann (2005), camuflando-se à medida que é visto pela sociedade como o "filtro" dos outros sistemas para informar - o que justifica a sua existência.

A leitura de uma notícia requer uma série de conhecimentos e embasamentos que a educação brasileira não pode oferecer à população. Poucas pessoas tem o acesso à informação tal como ela é, e são reféns diariamente de uma série de construções e produções, com objetivos definidos e alvos a serem atingidos.

A capacidade de agendamento de determinados veículos de comunicação no Brasil é reconhecida. Entretanto, esta realidade, por vezes, não é percebida pela maior parte da população, que muitas vezes toma o tema em discussões e sequer percebe de onde surgiu determinada afirmação, mas fatalmente já está interiorizada. No caso do "pibinho" parece ter se evidenciado um antídoto, um contra-agendamento, ou simplesmente um exagero na dose por parte da equipe editorial do jornal.

O poder exercido pela imprensa brasileira é ao mesmo tempo avassalador e sutil. Como alerta Bourdieu (2006), o uso dos sistemas simbólicos como instrumentos de dominação - as produções simbólicas - servem ao interesse da classe dominante, apresentados como interesses coletivos.

É uma espécie de violência intelectual a qual estamos todos submetidos diariamente, incapazes ou quase incapacitados de identificar como este poder recai em nosso cotidiano, nossas relações de trabalho, de consumo e até familiares. Por esta razão é tão importante o trabalho dos observatórios de mídia entre outras inciativas, sejam acadêmicas ou não.

Notadamente, o caso estudado não é suficiente para avaliar se o agendamento foi eficiente ou não, mas a partir da leitura dos outros veículos de comunicação e do acompanhamento do tema por outros atores que naturalmente se interessariam pelo tema, pode-se inferir que não houve êxito. O agendamento, de fato, não ocorreu, especialmente se consideramos os parâmetros que o universo digital permite acompanhar.

A série de mecanismos utilizados pode ter sido um fator complicador para que acontecesse tal agendamento. À primeira vista a notícia tem valor de manchete, mas durante a leitura é possível identificar certo excesso de elementos para sustentar o lead proposto, fortemente direcionados a demonstrar valor agregado do veículo na produção de dados, com uma intencionalidade discursiva bem definida.

Quando se observa a repercussão nas redes sociais verifica-se que os efeitos de sentido não resultaram em um processo de reconhecimento significativo que estimulasse sua replicação e circulação. Sequer animou um processo de semiose social mais significativo. Talvez uma possível pista de que o processo de horizontalização advinda da convergência entre meios analógicos e digitais tornou mais complexa a estratégia do agendamento. Talvez um 
indicador de que a sofisticação nas condições de recepção requerem novas competências das condições de produção.

Naturalmente este artigo não pretende esgotar o tema, e sim apresentar mais questões Às velhas questões na busca da compreensão dessas nuances entre comunicação, mídia e poder no Brasil. Os veículos e seus respectivos interesses quando não declarados abertamente tendem a criar - ou imaginam criar - uma percepção de imparcialidade e objetividade, que definitivamente, não existe.

\section{Referências}

Bourdieu, P. (2006). O poder simbólico. Rio de Janeiro: Bertrand Brasil.

Bourdieu, P. (1997). Sobre a Televisão. Rio de Janeiro: Jorge Zahar Ed.

Fraga, E. (2012). Renda per capita do país cai com 'pibinho'. Folha de S. Paulo. São Paulo. Folha Mercado, Caderno B, p. 11.

Habermas, J. (2003a). Mudança estrutural na esfera pública: investigações quanto a uma categoria da sociedade burguesa. Rio de Janeiro: Tempo Brasileiro.

Habermas, J. (2003b). Direito e democracia: entre facticidade e validade. Vol II. $2^{a}$ ed. Rio de Janeiro: Tempo Brasileiro.

Leitão, Miriam. (2012). Brasil está estagnado do ponto de vista do PIB per capita. Acessado em 30 de dezembro de 2012, em: <http://cbn.globoradio.globo.com/comentaristas/miriamleitao/2012/12/26/BRASIL-ESTA-ESTAGNADO-DO-PONTO-DE-VISTA-DO-PIB-PER-CAPTA.htm>.

Luhmann, N. (2005). A realidade dos meios de comunicação. São Paulo: Editora Paulus.

McCombs, M. (2009). A Teoria da Agenda: a mídia e a opinião pública. Petrópolis: Vozes.

Modé, Leandro. (2012). Estudo: PIB per capita cresce mais de 50\% em 4 áreas. Acessado em 28 de dezembro 2012, em: <http://economia.estadao.com.br/noticias/economia+geral,estudo-pib-per-capita-crescemais-de-50-em-4-areas, 139128,0.htm>.

Novelli, A. (2002). O projeto Folha e a negação do quarto poder. In L. G. Motta (org.), Imprensa e Poder (pp. 181-197). Brasília: Editora Universidade de Brasília.

Sodré, M. (2013). Antropológica do espelho: uma teria da comunicação linear e em rede. Petrópolis: Vozes.

Verón, E. (1993). La semiosis social. Barcelona: Editorial Gedisa.

Wolf, M. (2009). Teorias da Comunicação. Lisboa: Presença. 


\section{ANEXO A}

Renda per capita do país cai com 'pibinho'

Crescimento fraco da economia e desvalorização do real provocam maior recuo na riqueza em dólares desde 2002

Previsões para o futuro também preveem queda relativa do Brasil, que deve passar de $38^{\circ}$ para $39^{\circ}$ no mundo até 2022

\section{ÉRICA FRAGA}

DE SÃO PAULO

A renda dos brasileiros medida em dólares deverá sofrer o maior recuo em uma década em 2012 provocada pela expansão fraca do PIB (Produto Interno Bruto) e pela desvalorização do real.

O cenário de longo prazo do PIB per capita também mostra uma piora relativa a outros países porque as expectativas de expansão da economia caíram.

Dados compilados pela consultoria Consensus Forecast mostram que as projeções médias para o crescimento do PIB brasileiro no longo prazo recuaram de 4,5\% para 3,9\%, entre abril de 2010 e outubro deste ano.

A maior parte dos países teve revisões para baixo. Houve reduções grandes para China, zona do euro e Japão.

Mas, de forma geral, as quedas nas revisões foram menos significativas que a brasileira. Há também casos, como México e Alemanha, para os quais o cenário econômico melhorou um pouco.

Como resultado dessas e de outras tendências, o Brasil deve recuar, entre 2012 e 2022, do $38^{\circ}$ para o $39^{\circ}$ lugar (entre 52 países) no ranking de renda per capita elaborado pela Consensus Forecast (que coleta projeções de bancos e consultorias estrangeiros e nacionais).

Além da crise externa, "no Brasil há uma questão mais séria que é a incerteza regulatória. Isso tem afetado as decisões de investimento", afirma o economista Marcelo Moura, do Insper.

\section{QUEDA EM 2012}

A contração dos investimentos é a principal causa do desempenho fraco da economia brasileira neste ano. Economistas estimam que o PIB crescerá entre 0,8\% e 1,2\% em 2012 como um todo.

Como essa expansão da economia teve ritmo próximo ao do crescimento da população, a renda per capita ficará estagnada em reais. Mas recuará em dólares, já que a moeda brasileira se desvalorizou nesse período.

Segundo cálculos feitos pela consultoria EIU (Economist Intelligence Unit) a pedido da Folha, o PIB per capita em dólares deverá sofrer uma contração de cerca de $9 \%$ este ano, para US\$ 11.670 .

Será a queda mais forte desde 2002, quando houve recuo de 9,6\%. Em 2009, o PIB per capita em dólares também caiu $(2,9 \%)$ com uma recessão que, no entanto, foi parcialmente compensada por uma valorização do real.

A estimativa feita pela EIU para 2012 considera crescimento de $1 \%$ da economia e depreciação cambial média de cerca de $14 \%$ da moeda.

Segundo Robert Wood, analista da EIU, a queda do poder aquisitivo em dólares tem consequências de curto prazo relacionadas à capacidade de comprar bens importados, que ficam mais caros, e de viajar para o exterior.

No caso das empresas, o custo mais alto de importar máquinas e equipamentos é um dos fatores que causa queda dos investimentos. 
Mas, segundo Wood e outros economistas, o movimento do PIB per capita em um ano pode não revelar uma fotografia adequada do avanço da riqueza média da população. "Um histórico longo fornece uma ideia melhor do progresso do país", diz Wood.

Moura, do Insper, ressalta que a renda per capita do Brasil cresceu a uma média baixa, de $2,4 \%$ ao ano, entre 1964 e 2012. Segundo cálculos do economista, essa taxa saltou para 3,4\% entre 2006 e 2010 -período de expansão mais forte da economia.

"O problema é que esse ritmo mais forte não se manteve e há dúvidas de que o país possa retomá-lo de forma sustentável", diz Moura. 


\section{ANEXO B}

Estudo: PIB per capita cresce mais de $50 \%$ em 4 áreas

27 de dezembro de 2012

$\leftarrow$

LEANDRO MODÉ - Agência Estado

SÃO PAULO - O Brasil abriga 13 das 300 principais regiões metropolitanas do mundo, segundo um levantamento realizado pela Brookings Institution, uma entidade sem fins lucrativos com sede em Washington cuja missão é a realização de pesquisas independentes. O trabalho, elaborado em conjunto com o banco americano JP Morgan Chase, foi produzido para ajudar investidores a tomar suas decisões quando desejam abrir ou ampliar negócios no País. No fim de novembro, foi apresentado durante um evento em São Paulo.

Um dos pontos mais relevantes é o que comprova a descentralização da economia brasileira nos últimos anos. "O Produto Interno Bruto (PIB) per capita cresceu pelo menos $33 \%$ em todas as 13 regiões metropolitanas, mas em quatro (Grande Vitória, Recife, Curitiba e Baixada Santista) a expansão superou os 50\%", afirmou o pesquisador sênior da Brookings, Jill Wilson, lembrando que os dados comparam a situação do Brasil em 1990 e 2012. $\square \square$ O especialista também observa que, apesar das mudanças dos últimos anos, a economia brasileira ainda é altamente concentrada no litoral. "Apenas duas regiões (Manaus e Brasília) não estão na costa", disse.

Na avaliação de Wilson, o Brasil já pode ser considerado uma potência econômica global. "Ao longo das últimas três décadas, uma série de líderes políticos adotou medidas para estabilizar - País e fundar as bases para uma economia nova e dinâmica." $\square \square$ Apesar da melhora, o pesquisador nota que o País precisa avançar mais, sobretudo em termos de PIB per capita. "A maioria das regiões metropolitanas brasileiras tem uma renda per capita inferior à das regiões metropolitanas de países desenvolvidos, com exceção de Brasília", disse. $\square$ O especialista observa que os dados comparativos devem ser analisados com cuidado. "O PIB per capita da região metropolitana de São Paulo, por exemplo, é próximo ao de Portugal e supera o da região metropolitana do Porto. No entanto, equivale a apenas três quartos do PIB per capita de Lisboa", afirmou. Entre outros vários destaques do levantamento, Wilson chama a atenção para dois. O primeiro deles é que a pesquisa confirma a perda de espaço da indústria de manufatura na economia nacional. "A participação desse segmento no PIB do País caiu de $20 \%$ em 1990 para 16\% em 2012", afirmou. Nesse mesmo período, observou, aumentou a fatia de segmentos como agricultura, mineração, hotéis, serviços financeiros e serviços de informação.

\section{Pré-sal e o futuro}

Outro ponto interessante, de acordo com o pesquisador, diz respeito aos movimentos migratórios e imigratórios. Na Baixada Santista, por exemplo, a fatia da População Economicamente Ativa (PEA) que nasceu fora do Estado de São Paulo passou de 14\% em 1990 para $25 \%$ em 2012. A região é uma das mais promissoras do ponto de vista econômico em razão das descobertas do pré-sal.

Na contramão, a região metropolitana de Belo Horizonte viu encolher, no mesmo período, a participação dos não nascidos em Minas Gerais na PEA: de $14 \%$ para 5,8\%. Em termos de imigração, Wilson observa que a Grande Vitória registrou a maior taxa no censo de 2010 do Instituto Brasileiro de Geografia e Estatística (IBGE): 5,7 em cada 1.000 habitantes deixaram a localidade. Ele lembra, ainda, que 30\% desses imigrantes foram para Portugal, outros 30\% para os Estados Unidos e $13 \%$ se mudaram para a Itália. 